\title{
Satellite Scheduling with VieSched ++ : current status and future plans
}

\section{Other Conference Item}

\section{Author(s):}

Wolf, Helene; Schartner, Matthias (D); Böhm, Johannes; Hellerschmied, Andreas

Publication date:

2020-05-05

Permanent link:

https://doi.org/10.3929/ethz-b-000459552

Rights / license:

Creative Commons Attribution 4.0 International

Originally published in:

EGUsphere, https://doi.org/10.5194/egusphere-egu2020-13254 
EGU2020-13254

https://doi.org/10.5194/egusphere-egu2020-13254

EGU General Assembly 2020

(c) Author(s) 2021. This work is distributed under

the Creative Commons Attribution 4.0 License.

\title{
Satellite Scheduling with VieSched++ : current status and future plans
}

\author{
Helene Wolf ${ }^{1}$, Matthias Schartner ${ }^{1}$, Johannes Böhm ${ }^{1}$, and Andreas Hellerschmied ${ }^{2}$ \\ ${ }^{1}$ Department of Geodesy and Geoinformation, Advanced Geodesy, TU Wien, Vienna, Austria (helene.wolf@geo.tuwien.ac.at) \\ ${ }^{2}$ Bundesamt für Eich- und Vermessungswesen, Vienna, Austria
}

Observing extragalactic radio sources is an integral part of Very Long Baseline Interferometry (VLBI) but observing satellites also provides a variety of new possibilities. Interesting scientific applications can be found in providing space ties instead of using local ties for connecting reference frames of different space-geodetic techniques. To generate schedules including observations to satellites a dedicated module has been implemented in the new scheduling software VieSched++.

This newly developed module determines possible satellite observations considering several observation conditions, such as the visibility from the selected station network and antenna slew rates. A schedule including observations to quasars and satellites can be generated in a semiautomatic mode. The scheduling of the satellite scans is done manually by the user who can select and adjust the possible satellite observations before adding them to the schedule. The remaining part of the schedule is filled automatically by the software VieSched++ using the general optimization algorithm with observations to quasars. In this poster an overview of the current status of the satellite scheduling module in VieSched++ is given, as well as an outlook to highlight future plans. 